\title{
Effect of Goreisan, a traditional Japanese Kampo medicine, on postoperative nausea and vomiting in gynecological patients
}

\author{
Keiko Kume, Yusuke Kasuya* and Makoto Ozaki
}

\begin{abstract}
Background: Goreisan, a traditional Japanese Kampo medicine, may prevent postoperative nausea and vomiting (PONV). The purpose of this study was to evaluate the effect of Goreisan on PONV in a high-risk population in a randomized, double-blind, placebo-controlled manner.

Findings: Patients undergoing gynecological surgery were randomly allocated to the Goreisan and the control groups. General anesthesia was induced with propofol and remifentanil. After endotracheal intubation, anesthesia was maintained with sevoflurane, fentanyl, and remifentanil. Goreisan $7.5 \mathrm{~g}$ dissolved in water (Goreisan group) or water (control group) in a volume of $20 \mathrm{ml}$ was administered through a nasogastric tube approximately $1 \mathrm{~h}$ before completion of surgery. The primary outcome of this study was the incidence of PONV during the first $2 \mathrm{~h}$ after extubation. In the interim analysis, it was apparent that Goreisan has no effect. Therefore, we discontinued recruiting patients and present results based on data from 83 patients. The incidence of PONV during the first $2 \mathrm{~h}$ after extubation was $45 \%$ in the Goreisan group $(n=40)$ and $46.5 \%$ in the control group $(n=43)(p=0.89)$. There was no significant difference in PONV incidence or severity during the first $24 \mathrm{~h}$ post-extubation.
\end{abstract}

Conclusion: Goreisan has little potency in preventing PONV in high-risk patients.

Keywords: Postoperative nausea and vomiting, Goreisan, Kampo medicine, Gynecological surgery, General anesthesia

\section{Findings} Introduction

The incidence of postoperative nausea and vomiting (PONV) has been reported to be around 30\% [1, 2]. PONV, alongside postoperative pain, is a distress, decreasing patient satisfaction and increasing the risk of dehydration, electrolyte disorder, aspiration pneumonia, prolongation of being bedridden, and delaying discharge $[3,4]$. The guidelines for PONV have been updated based on many clinical studies $[5,6] .5-\mathrm{HT}_{3}$ receptor antagonists, including ondansetron, are the gold standard antiemetics $[7,8]$, and NK-1 receptor antagonists are also reported to be as effective as $5-\mathrm{HT}_{3}$ receptor antagonists $[9,10]$. However, $5-\mathrm{HT}_{3}$ and NK-1 receptor antagonists have not been approved for routine use by the Japanese Ministry of Health, Labor and Welfare as part of

\footnotetext{
* Correspondence: kasuyay@mb.infoweb.ne.jp Department of Anesthesiology, Tokyo Women's Medical University, 8-1, Kawada-cho, Shinjuku-ku, Tokyo 162-8666, Japan
}

the public medical insurance coverage for perioperative antiemetics due to high cost. Only metoclopramide is approved as a perioperative antiemetic in Japan. However, metoclopramide alone is not sufficiently effective to prevent PONV [11]. Because of this Japanese-specific circumstance, a highly effective and low-cost antiemetic with few adverse effects is desired for the prevention of PONV.

Goreisan consists of five herbal galenicals, "Takusha" (Alismatis rhizoma), "Bukuryo" (hoelen), "Sojutsu" (Atractylodis lanceae rhizoma), "Keihi" (cinnamon bark), and "Chorei" (Polyporus), and has been traditionally used as a "hydrostatic modulator" to treat edema, diarrhea, headache, nausea, and dizziness [12]. Although Goreisan increases urine output, like diuretics and furosemide, Goreisan has little effect on the blood electrolyte balance and it does not have diuretic activity in dehydrated individuals. The hydrostatic modulation of Goreisan is considered milder and causes fewer side effects than other diuretics [13]. Goreisan has also been reported to 
regulate the function of the intestines and show an antiemetic effect [14-16].

In this study, we evaluated the efficacy of Goreisan to prevent PONV in a high-risk patient population undergoing gynecological surgery, with the use of intraoperative volatile anesthetics and postoperative opioids.

\section{Methods}

This prospective, randomized, placebo-controlled clinical study was conducted with the approval of the institutional research board of Tokyo Women's Medical University and was preregistered as UMIN-000011801 in the University Hospital Medical Information Network Clinical Trials Registry. All patients involved in the study provided written informed consent. Inclusion criteria were patients who (1) underwent elective gynecological surgery, (2) were aged 20 to 50 years, and (3) had an expected procedure time of $>2 \mathrm{~h}$. Exclusion criteria were (1) ASA-PS 3 or more, (2) morbid obesity (body mass index $\geq 35 \mathrm{~kg} / \mathrm{m}^{2}$ ), (3) pregnant or lactating women, (4) regular use of any Kampo medicines, and (5) use of steroids, immunosuppressive, or chemotherapy agents.

\section{Anesthesia and postoperative protocol}

Patients were not given any premedication. General anesthesia was induced with $1-2 \mathrm{mg} / \mathrm{kg}$ of propofol, $0.5 \mu \mathrm{g} / \mathrm{kg} / \mathrm{min}$ of remifentanil, and $0.6 \mathrm{mg} / \mathrm{kg}$ of rocuronium and maintained with sevoflurane to keep the bispectral index (BIS) value between 40 and 60. The remifentanil dose was fixed at $0.5 \mu \mathrm{g} / \mathrm{kg} / \mathrm{min}$ throughout the procedure, and total intraoperative fentanyl dose was intended to be $8-12 \mu \mathrm{g} / \mathrm{kg}$. Postoperative analgesia was established by using an intravenous patient-controlled analgesia pump with fentanyl, at a base dose of $20 \mu \mathrm{g} / \mathrm{h}$ and bolus dose of $20 \mu \mathrm{g}$ with a 10-min lockout interval.

\section{Intervention}

After the induction of general anesthesia, patients were assigned to the Goreisan group or control group according to a computer-generated randomization. Assignment was blinded except for the independent investigators who prepared and administered the test drugs.

After the trachea was intubated, a nasogastric tube was inserted and the placement was confirmed by aspiration of gastric fluid. Approximately $1 \mathrm{~h}$ prior to the completion of the surgery, the patients in the Goreisan group were administered $7.5 \mathrm{~g}$ of Goreisan (Extracts of Alismatis rhizoma $4.0 \mathrm{~g}$, Bukuryo $3.0 \mathrm{~g}$, Atractylodis lanceae rhizoma $3.0 \mathrm{~g}$, cinnamon bark $1.5 \mathrm{~g}$, and Polyporus $3.0 \mathrm{~g}$ ) dissolved in $20 \mathrm{~mL}$ of water at $40{ }^{\circ} \mathrm{C}$. Patients in the control group were administered $20 \mathrm{~mL}$ of water at $40{ }^{\circ} \mathrm{C}$ as a placebo.

\section{Measurements and statistics}

PONV just after extubation and at $30 \mathrm{~min}$ and 2,6 , and $24 \mathrm{~h}$ after extubation were assessed by an anesthesiologist who was blinded the assignment. Nausea severity was rated using a 4-point scale (0: none, 1: slight, 2: moderate, 3: severe). Pain severity was rated using an 11-point scale (0: no pain, 10: severest). Postoperative antiemetic use was also recorded.

The PONV score (smoking history and history of motion sickness or PONV) and fluid disturbance score, which is a criterion for administering Goreisan in traditional Kampo medicine, were assessed preoperatively.

The primary outcome of this study was the incidence of PONV during the first $2 \mathrm{~h}$ after extubation. Secondary outcomes were the incidence and severity of PONV at $30 \mathrm{~min}$ and 6 and $24 \mathrm{~h}$ after extubation and the requirement of antiemetic use.

The unpaired $t$ test or Mann-Whitney U-test was used for comparisons of continuous demographic variables, and the chi-square test or Fisher's exact test was used for nominal variables. A chi-square test and repeatedmeasures two-way ANOVA were performed to compare the incidence and severity of PONV. The statistical analyses were conducted using $\mathrm{JMP}^{\circ}$ ver.12.1.0 (SAS Institute Inc., Cary, NC). $p<0.05$ was considered to indicate statistical significance.

\section{Sample size estimation}

Generally, the incidence of PONV is reported to be 30 to $50 \%$. Since this study population was considered to be at high risk of developing PONV (undergoing gynecological surgery, and use of volatile anesthetics and postoperative opioids), we estimated the baseline PONV incidence seemed to be approximately $50 \%$. As ondansetron, the most effective PONV preventive medicine reduces PONV incidence by 25 to $60 \%$ [17-19], we considered that a reduction of $40 \%$ in PONV incidence after treatment with Goreisan would be satisfactory. As we calculated that a sample size of 186 patients (93 patients in each) would be needed in order to detect a $40 \%$ difference in the incidence of PONV, with an $\alpha$ value of 0.05 and a power of $80 \%$, we planned to recruit a total of 200 patients (100 patients in each group), and an interim analysis was planned when the study reached 90 patients.

\section{Results}

After performing the interim analysis, we decided to discontinue the study due to futility. Therefore, this manuscript presents the results of the interim analysis. During the period from February 2014 to March 2015, a total of 470 gynecological surgeries were performed in our institution, and 214 patients among those were considered eligible for the study. After reviewing the medical charts, 103 patients were excluded due to the 


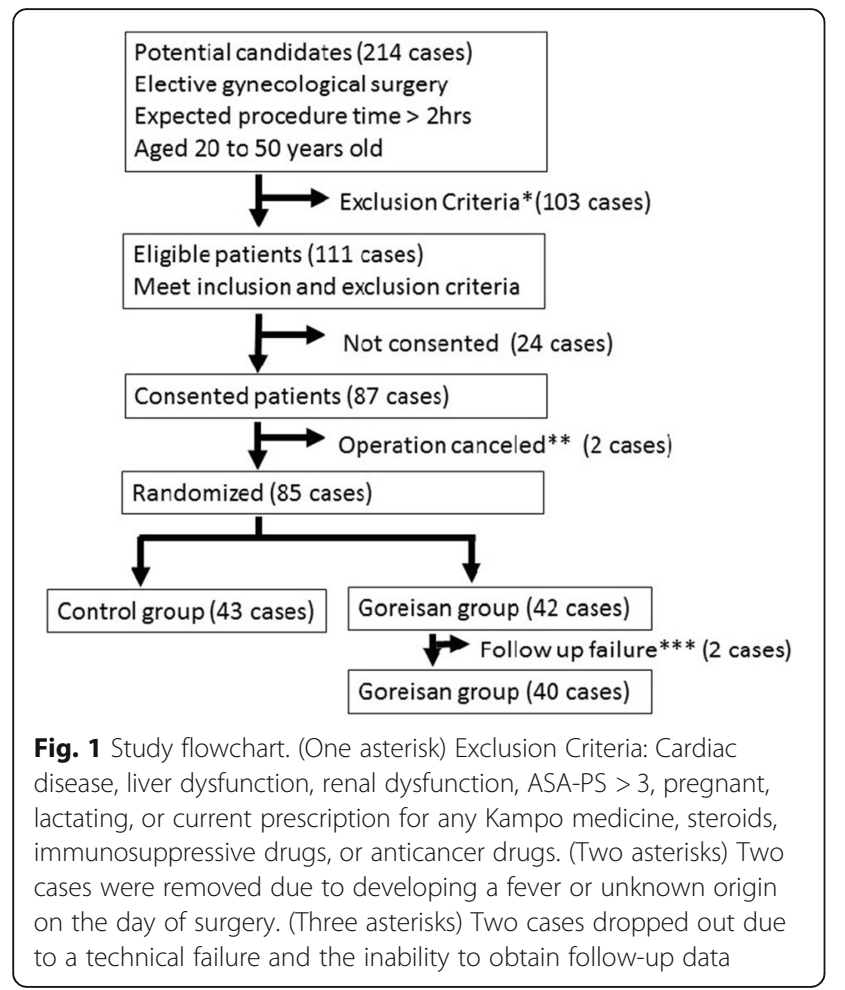

exclusion criteria, and after an interview, 24 patients did not consent to participate in the study. Two patients were removed from the study after developing a fever of unknown cause after providing informed consent, and in two patients, postoperative data could not be obtained because of a technical follow-up failure. As a result, 83 cases were completed and analyzed (Goreisan group, 40 cases, and control group, 43 cases) (Fig. 1).

The patient demographics did not differ between groups (Table 1). Preoperative PONV risk assessment revealed no significant differences concerning motion sickness, previous PONV history, dizziness, or smoking history (Table 2). The fluid disturbance score was not significantly different between groups (Table 3 ). Intraoperative and postoperative parameters were shown in Table 4.

The cumulative incidence of nausea and vomiting at the time of extubation, at $30 \mathrm{~min}$, at $2 \mathrm{~h}$, and at $24 \mathrm{~h}$ after extubation were shown in Table 5 . Nausea severity, pain severity, and antiemetic and analgesic use were not different between groups (Tables 6 and 7).

Table 1 Patient demographics

\begin{tabular}{llll}
\hline & Control $(n=43)$ & Goreisan $(n=40)$ & $p$ value \\
\hline Age (years) & $38.5 \pm 8.0$ & $37.9 \pm 8.0$ & 0.73 \\
Body weight $(\mathrm{kg})$ & $57.5 \pm 10.3$ & $56.9 \pm 11.8$ & 0.81 \\
Height $(\mathrm{cm})$ & $159.1 \pm 5.9$ & $158.9 \pm 5.8$ & 0.90 \\
Body mass index $\left(\mathrm{kg} / \mathrm{m}^{2}\right)$ & $22.5 \pm 4.3$ & $22.4 \pm 4.9$ & 0.91 \\
\hline
\end{tabular}

Data are expressed as mean \pm standard deviation
Table 2 Preoperative PONV risk factors

\begin{tabular}{llll}
\hline PONV risk factor & Control $(n=43)$ & Goreisan $(n=40)$ & $p$ value \\
\hline Motion sickness & $21(48.8 \%)$ & $17(42.5 \%)$ & 0.57 \\
PONV history & $1(2.3 \%)$ & $4(10 \%)$ & 0.15 \\
Dizziness & $9(20.9 \%)$ & $12(30 \%)$ & 0.35 \\
Smoking history & $11(25.6 \%)$ & $10(25 \%)$ & 0.95 \\
\hline
\end{tabular}

Data are expressed as frequencies and percentage

$P O N V$ postoperative nausea and vomiting

\section{Discussion}

This study was designed to detect the positive difference in PONV incidence between groups; however, study hypothesis was declined. This study showed that Goreisan has no potency in preventing PONV in the first $24 \mathrm{~h}$ postextubation. These results disagree with those of Kori et al. [20]. They administered $7.5 \mathrm{~g}$ of Goreisan orally the day before surgery and found that it had a significant effect on PONV. As Goreisan is usually administered $7.5 \mathrm{~g}$ daily

Table 3 Fluid disturbance scores

\begin{tabular}{|c|c|c|c|c|}
\hline & Score $^{a}$ & $\begin{array}{l}\text { Control } \\
(n=43)\end{array}$ & $\begin{array}{l}\text { Goreisan } \\
(n=40)\end{array}$ & $p$ value \\
\hline Heaviness of the body & 3 & 10 & 12 & 0.49 \\
\hline Throbbing headache & 4 & 8 & 7 & 0.90 \\
\hline Heaviness of the head & 3 & 14 & 8 & 0.20 \\
\hline Motion sickness & 5 & 21 & 18 & 0.73 \\
\hline Dizziness & 5 & 8 & 10 & 0.48 \\
\hline $\begin{array}{l}\text { Lightheadedness upon } \\
\text { standing }\end{array}$ & 5 & 10 & 16 & 0.1 \\
\hline Watery nasal discharge & 3 & 13 & 8 & 0.28 \\
\hline Excessive salivary & 3 & 3 & 4 & 0.62 \\
\hline Foamy sputum & 4 & 2 & 2 & 0.94 \\
\hline Nausea or vomiting & 3 & 4 & 1 & 0.20 \\
\hline Hyperdynamic bowel sounds & 3 & 12 & 13 & 0.65 \\
\hline Morning stiffness & 7 & 2 & 4 & 0.35 \\
\hline $\begin{array}{l}\text { Splashing sound in epigastric } \\
\text { region or edematous }\end{array}$ & 15 & 1 & 3 & 0.27 \\
\hline $\begin{array}{l}\text { Pleural effusion, cardiac } \\
\text { effusion, or ascites }\end{array}$ & 15 & 0 & 0 & NA \\
\hline $\begin{array}{l}\text { Brisk pulsation in the } \\
\text { supra-umbilical region }\end{array}$ & 5 & 14 & 15 & 0.64 \\
\hline Watery diarrhea & 5 & 1 & 2 & 0.51 \\
\hline Oliguria & 7 & 0 & 2 & 0.14 \\
\hline Polyuria & 5 & 8 & 14 & 0.09 \\
\hline Fluid disturbance score & & $6.5[4-9.25]$ & $7[5-11.125]$ & 0.24 \\
\hline
\end{tabular}

Data are expressed as frequencies in each fluid disturbance component, and fluid disturbance score are reported as median with quartile range

aThe Kampo medicine diagnostic criteria for "fluid disturbance" were evaluated using a simple questionnaire filled by self-assessment. The sum total of each component score is calculated as the fluid disturbance score. If the fluid disturbance score is $\geq 13$, the patient is regarded as being in a state of "fluid disturbance." (If the extent of each symptom is slight, half of the total score was given) 
Table 4 Intraoperative and postoperative parameters

\begin{tabular}{llll}
\hline & Control & Goreisan & $p$ value \\
\hline Pre-operative heart rate $(\mathrm{bpm})$ & $75 \pm 11$ & $73 \pm 10$ & 0.27 \\
Pre-operative sBP $(\mathrm{mmHg})$ & $115 \pm 16$ & $115 \pm 15$ & 0.83 \\
Pre-operative dBP $(\mathrm{mmHg})$ & $72 \pm 12$ & $71 \pm 11$ & 0.88 \\
Pre-operative body temperature $\left({ }^{\circ} \mathrm{C}\right)$ & $36.6 \pm 0.3$ & $36.7 \pm 0.4$ & 0.35 \\
Laparotomy/laparoscopy & $21 / 22$ & $24 / 16$ & 0.31 \\
Procedure time $(\mathrm{min})$ & $132 \pm 56$ & $131 \pm 44$ & 0.93 \\
Anesthesia time $(\mathrm{min})$ & $170 \pm 60$ & $174 \pm 41$ & 0.78 \\
Crystalloid volume $(\mathrm{mL})$ & $1439 \pm 639$ & $1495 \pm 512$ & 0.66 \\
Colloid volume $(\mathrm{mL})$ & $23 \pm 107$ & $52 \pm 220$ & 0.43 \\
Transfusion (mL) & 0 & $28 \pm 110$ & 0.1 \\
Urine (mL) & $144 \pm 186$ & $91 \pm 84$ & 0.1 \\
Blood loss (g) & $142 \pm 274$ & $254 \pm 423$ & 0.15 \\
Intra operative fentanyl $(\mu \mathrm{g})$ & $550 \pm 98$ & $530 \pm 118$ & 0.4 \\
Intra operative remifentanil $(\mathrm{mg})$ & $4.1 \pm 1.4$ & $4.2 \pm 1.2$ & 0.75 \\
Postoperative fentanyl $(\mu \mathrm{g})$ & $802 \pm 357$ & $882 \pm 382$ & 0.33 \\
\hline
\end{tabular}

Continuous variables reported as mean \pm standard deviation, and categorical variable reported as frequencies

$s B P$ systolic blood pressure, $d B P$ diastolic blood pressure

divided by 3 times (each $2.5 \mathrm{~g}$ ), authors considered $7.5 \mathrm{~g}$ of Goreisan is the almost maximum dose for single administration. We administered $7.5 \mathrm{~g}$ of Goreisan dissolved to $20 \mathrm{ml}$ of water intraoperatively through a gastric tube at approximately $1 \mathrm{~h}$ before the end of the procedure because Goreisan has a quick onset. However, general anesthesia and laparotomy may reduce digestive tract activity, and the absorption of Goreisan may be delayed. In two of three patients who vomited within $2 \mathrm{~h}$ after extubation, the vomit apparently included Goreisan, which has a characteristic color and herbal scent. It indicated that Goreisan may not have been sufficiently absorbed at the end of the procedure in other patients. Even if absorption of

Table 5 Accumulative incidence of nausea and vomiting

\begin{tabular}{llll}
\hline & Control $(n=43)$ & Goreisan $(n=40)$ & \\
\hline Incidence of nausea & & & \\
At extubation & $3(7.0 \%)$ & $4(10 \%)$ & 0.63 \\
To 30 min & $14(32.6 \%)$ & $15(37.5 \%)$ & 0.64 \\
To 120 min & $20(46.5 \%)$ & $18(45 \%)$ & 0.89 \\
To 6 h & $28(65.1 \%)$ & $27(67.5 \%)$ & 0.82 \\
To 24 h & $30(69.8 \%)$ & $31(77.5 \%)$ & 0.43 \\
Incidence of vomiting & & \\
At extubation & 0 & 0 & NA \\
To 30 min & $1(2.3 \%)$ & $1(2.5 \%)$ & 0.96 \\
To 120 min & $5(11.6 \%)$ & $3(7.5 \%)$ & 0.53 \\
To 6 h & $11(25.6 \%)$ & $6(15 \%)$ & 0.23 \\
To 24 h & $21(48.8 \%)$ & $23(57.5 \%)$ & 0.43 \\
\hline
\end{tabular}

Data are expressed as frequencies and percentage
Table 6 Nausea severity and antiemetic use

\begin{tabular}{|c|c|c|c|}
\hline & Control $(n=43)$ & Goreisan $(n=40)$ & $p$ value \\
\hline \multicolumn{4}{|l|}{ Nausea severity } \\
\hline At extubation & $0[0-0]$ & $0[0-0]$ & 0.45 \\
\hline To $30 \mathrm{~min}$ & $0[0-1]$ & $0[0-1]$ & 0.84 \\
\hline $30 \mathrm{~min}$ to $2 \mathrm{~h}$ & $0[0-1]$ & $0[0-0]$ & 0.20 \\
\hline $2 \mathrm{~h}$ to $6 \mathrm{~h}$ & $0[0-2]$ & $0[0-1.25]$ & 0.82 \\
\hline $6 \mathrm{~h}$ to $24 \mathrm{~h}$ & $1[0-3]$ & $2[0-3]$ & 0.22 \\
\hline \multicolumn{4}{|c|}{ Antiemetic medicine use } \\
\hline At extubation & 0 & 0 & NA \\
\hline To $30 \mathrm{~min}$ & 0 & $1(2.5 \%)$ & 0.3 \\
\hline $30 \mathrm{~min}$ to $2 \mathrm{~h}$ & $3(7.0 \%)$ & $4(10.0 \%)$ & 0.62 \\
\hline $2 \mathrm{~h}$ to $6 \mathrm{~h}$ & $9(20.9 \%)$ & $3(7.5 \%)$ & 0.08 \\
\hline $6 \mathrm{~h}$ to $24 \mathrm{~h}$ & $18(41.9 \%)$ & 15 (41.9\%) & 0.56 \\
\hline
\end{tabular}

Goreisan delayed, because the incidence of PONV in the first $24 \mathrm{~h}$ after extubation were similar in the control and Goreisan groups, we can conclude the effect of Goreisan on PONV was clinically negligible.

Although the pharmacological activity of Goreisan has not been fully revealed, we hypothesized that the diuretic effect and drainage of water retained in the interstitial space and improvement of gastrointestinal motility might contribute to preventing PONV [13, 21]. The mechanism of PONV is complex and may include the stimulation of the chemoreceptor trigger zone by residual anesthetic, vestibular nerve disability, diminished peristalsis, elevated digestive tract inner pressure, and psychological reasons. As all of these mechanisms

Table 7 Pain severity and pain relief medication

\begin{tabular}{llll}
\hline & Control & Goreisan & $p$ value \\
\hline Pain severity & & & \\
At extubation & $2[0-3]$ & $1[0-4]$ & 0.88 \\
To 30 min & $4[2-7]$ & $5[3-7]$ & 0.44 \\
30 min to 2 h & $3[2-4]$ & $3[2-4]$ & 0.90 \\
2 h to 6 h & $2[1-2]$ & $2[1-3]$ & 0.46 \\
6 h to 24 h & $2[1-3.5]$ & $2[1-3]$ & 0.26 \\
Pain relief medication & & & \\
At extubation & 0 & 0 & NA \\
To 30 min & $10(23.3 \%)$ & $9(22.5 \%)$ & 0.94 \\
30 min to 2 h & $5(11.6 \%)$ & $4(10 \%)$ & 0.81 \\
2 h to 6 h & $5(11.6 \%)$ & $5(12.5 \%)$ & 0.90 \\
6 h to 24 h & $12(27.9 \%)$ & $11(27.5 \%)$ & 0.97 \\
\hline
\end{tabular}

Pain severity was measured using an 11-point scale (0: no pain, 10: severest). Data in pain severity are shown as the median and interquartile range. Data in pain relief medication are expressed as frequencies and percentage 
can cause PONV, a single administration of Goreisan is insufficient in preventing PONV in a high-risk population.

We randomized patients without considering the water disturbance score. As the efficacy of Kampo medicines depends on the patient's individual constitution, diagnostic Kampo medicine-specific examination is very important $[12,22]$. In this study, around $30 \%$ of patients were identified as being in a state of water disturbance (water disturbance score more than 13). Even if we focused on patients with water disturbance, Goreisan still had no significant effect on PONV.

In this study, Goreisan was given only once during the procedure. In the original traditional Kampo medicine, patients are required to keep taking medicines for about 1 month to ameliorate body constitution. However, practically long time preconditioning before the surgical procedure is not realistic.

This was a negative study on showing PONV prophylactic effect by Goreisan, and showed an incidence of PONV within $24 \mathrm{~h}$ in this study population was very high. $5-\mathrm{HT}_{3}$ receptor antagonists, like ondansetron and granisetron which have strong evidence and have been world widely used, should be approved for PONV prophylactic use in Japan. Under limited circumstance like in Japan, conservative methods such as avoiding volatile anesthetics and minimizing postoperative opioid use are the only options to reduce the incidence of PONV in high-risk population. In conclusion, Goreisan has little potency in preventing PONV in high-risk patients.

\section{Acknowledgements}

We would like to thank Dr. Hiroko Iwakiri for contributing to the collection of the patient's data and designing this study and Dr. Ryu Komatsu for contributing to the editing of the English manuscript.

\section{Funding}

This study receives funding from the Department of Anesthesiology, Tokyo Women's Medical University.

\section{Author's contributions}

KK is responsible for the study design, data collection, data analysis, and writing of the first draft of the paper. YK participated in the study design, data collection, data analysis, and editing of the manuscript. MO coordinated the study protocol and assisted in drafting the paper. All authors read and approved the final manuscript.

\section{Ethics approval and consent to participate}

This study was conducted with the approval of the institutional research board of Tokyo Women's Medical University (No. 131004, 20 December 2013).

\section{Competing interests}

The authors declare they have no competing interests.

Received: 28 August 2017 Accepted: 22 September 2017

Published online: 29 September 2017

\section{References}

1. Apfel CC, Laara E, Koivuranta M, Greim CA, Roewer N. A simplified risk score for predicting postoperative nausea and vomiting: conclusions from crossvalidations between two centers. Anesthesiology. 1999;91:693-700.
2. Morino R, Ozaki M, Nagata O, Yokota M. Incidence of and risk factors for postoperative nausea and vomiting at a Japanese Cancer Center: first largescale study in Japan. J Anesth. 2013;27:18-24.

3. Gan TJ, Meyer T, Apfel CC, Chung F, Davis PJ, Eubanks S, Kovac A, Philip BK, Sessler DI, Temo J, Tramer MR, Watcha M. Department of Anesthesiology DUMC: Consensus guidelines for managing postoperative nausea and vomiting. Anesth Analg. 2003;97:62-71.

4. Apfel CC, Kranke P, Katz MH, Goepfert C, Papenfuss T, Rauch S, Heineck R, Greim CA, Roewer N. Volatile anaesthetics may be the main cause of early but not delayed postoperative vomiting: a randomized controlled trial of factorial design. Br J Anaesth. 2002;88:659-68.

5. Gan TJ, Meyer TA, Apfel CC, Chung F, Davis PJ, Habib AS, Hooper VD, KovaC AL, Kranke P, Myles P, Philip BK, Samsa G, Sessler DI, Temo J, Tramer MR, Vander Kolk C, Watcha M. Society for Ambulatory A: Society for Ambulatory Anesthesia guidelines for the management of postoperative nausea and vomiting. Anesth Analg. 2007;105:1615-28.

6. Gan TJ, Diemunsch P, Habib AS, Kovac A, Kranke P, Meyer TA, Watcha M, Chung F, Angus S, Apfel CC, Bergese SD, Candiotti KA, Chan MT, Davis PJ, Hooper VD, Lagoo-Deenadayalan S, Myles P, Nezat G, Philip BK, Tramer MR. Society for Ambulatory A: Consensus guidelines for the management of postoperative nausea and vomiting. Anesth Analg. 2014;118:85-113.

7. Gan TJ, Sinha AC, Kovac AL, Jones RK, Cohen SA, Battikha JP, Deutsch JS, Pergolizzi JV Jr, Group TDSS, Glass PS. A randomized, double-blind, multicenter trial comparing transdermal scopolamine plus ondansetron to ondansetron alone for the prevention of postoperative nausea and vomiting in the outpatient setting. Anesth Analg. 2009;108:1498-504.

8. Sane S, Hasanlui MV, Abbasivash R, Mahoori A, Hashemi ST, Rafiei F. Comparing the effect of intravenous dexamethasone, intravenous ondansetron, and their combination on nausea and vomiting in cesarean section with spinal anesthesia. Adv Biomed Res. 2015;4:230.

9. Ham SY, Shim YH, Kim EH, Son MJ, Park WS, Lee JS. Aprepitant for antiemesis after laparoscopic gynaecological surgery: a randomised controlled trial. Eur J Anaesthesiol. 2016;33:90-5.

10. Kawano H, Matsumoto T, Hamaguchi E, Manabe S, Nakagawa M, Yamada A, Fujimoto M, Tada F. Antiemetic efficacy of combined aprepitant and dexamethasone in patients at high-risk of postoperative nausea and vomiting from epidural fentanyl analgesia. Minerva Anestesiol. 2015;81:362-8.

11. De Oliveira GS Jr, Castro-Alves LJ, Chang R, Yaghmour E, RJ MC Systemic metoclopramide to prevent postoperative nausea and vomiting: a meta-analysis without Fujii's studies. Br J Anaesth. 2012;109:688-97.

12. Terasawa K. Evidence-based reconstruction of Kampo medicine: part II-the concept of Sho. Evid Based Complement Alternat Med. 2004;1:119-23.

13. Fukutomi $O$, Sakurai $S$, Nada K, Morita H, Arai T, Suzuki K, Aoki Y. Study of effect of Goreisan enema on acute gastroenteritis of children. J Traditional Med. 2006;23:151-2

14. Okui Y, Morita M, lizuka A, Komatsu Y, Okada M, Maruno M, Niijima A. Effects of Hoelen on the efferent activity of the gastric vagus nerve in the rat. Jpn J Pharmacol. 1996;72:71-3.

15. Nishi K, Takata K, Asano S: Effects of goreisan suppository on vomiting in children-comparison with domperidone suppository. Nihon Byoin Yakuzaishikai Zasshi (J Jpn Soc Hosp Pharm) 1998; 34: 1173-1176.

16. Yamada K, Yagi G, Kanba S. Effectiveness of Gorei-san (TJ-17) for treatment of SSRI-induced nausea and dyspepsia: preliminary observations. Clin Neuropharmacol. 2003;26:112-4

17. Bolton CM, Myles PS, Carlin JB, Nolan T. Randomized, double-blind study comparing the efficacy of moderate-dose metoclopramide and ondansetron for the prophylactic control of postoperative vomiting in children after tonsillectomy. Br J Anaesth. 2007;99:699-703.

18. Stevens AJ, Woodman RJ, Owen $\mathrm{H}$. The effect of ondansetron on the efficacy of postoperative tramadol: a systematic review and meta-analysis of a drug interaction. Anaesthesia. 2015;70:209-18.

19. Song JW, Park EY, Lee JG, Park YS, Kang BC, Shim YH. The effect of combining dexamethasone with ondansetron for nausea and vomiting associated with fentanyl-based intravenous patient-controlled analgesia. Anaesthesia. 2011;66:263-7.

20. Kori K, Oikawa T, Odaguchi H, Omoto H, Hanawa T, Minami T. Go-rei-San, a Kampo medicine, reduces postoperative nausea and vomiting: a prospective, single-blind, randomized trial. J Altern Complement Med. 2013;19:946-50. 
21. Wakabayashi Y, Yamashita M, Asano T, Yamada A, Kenai H, Kondoh Y, Hori Y, Nagatomi H. Effect of Gorei-san with tranexamic acid for preventing recurrence of chronic subdural hematoma. No Shinkei Geka. 2012;40:967-71.

22. Arai M, Arai K, Hioki C, Takashi M, Matsumoto K, Honda M, Izumi S.

Evaluation of medical students using the "qi, blood, and fluid" system of Kampo medicine. Tokai J Exp Clin Med. 2013;38:37-41.

\section{Submit your manuscript to a SpringerOpen ${ }^{\circ}$} journal and benefit from:

- Convenient online submission

- Rigorous peer review

- Open access: articles freely available online

- High visibility within the field

- Retaining the copyright to your article

Submit your next manuscript at $\gg$ springeropen.com 